American Journal of Applied Sciences 5 (3): 242-247, 2008

ISSN 1546-9239

(C) 2008 Science Publications

\title{
Transmission Congestion Management by Determining Optimal Location of FACTS Devices in Deregulated Power Systems
}

\author{
Seyed Abbas Taher, Hadi Besharat \\ Department of Electrical Engineering, University of Kashan, Kashan, Iran
}

\begin{abstract}
In a deregulated electricity market, it may always not be possible to dispatch all of the contracted power transactions due to congestion of the transmission corridors. The ongoing power system restructuring requires an opening of unused potentials of transmission system due to environmental, right-of-way and cost problems which are major hurdles for power transmission network expansion. Flexible ac transmission systems devices can be an alternative to reduce the flows in heavily loaded lines, resulting in an increased loadability, low system loss, improved stability of the network, reduced cost of production and fulfilled contractual requirement by controlling the power flows in the network. A method to determine the optimal location of thyristor controlled series compensators has been suggested in this paper based on real power performance index and reduction of total system reactive power loss.
\end{abstract}

Keywords: Congestion, Optimal Location, Deregulated Power System

\section{INTRODUCTION}

In a competitive electricity market, congestion occurs when the transmission network is unable to accommodate all of the desired transactions due to a violation of system operating limits. Congestion does occur in both electrically bundled and unbundled systems but the management in the bundled system is relatively simple as generation, transmission, and in some cases, distribution systems are managed by one utility. The management of congestion is somewhat more complex in competitive power markets and leads to several disputes.

In the present day competitive power market, each utility manages the congestion in the system using its own rules and guidelines utilizing a certain physical or financial mechanism ${ }^{[1]}$.

The limitations of a power transmission network arising from environmental, right-of-way and cost problems are fundamental to both bundled and unbundled power systems. Patterns of generation that result in heavy flows tend to incur greater losses, and to threaten stability and security, ultimately make certain generation patterns economically undesirable ${ }^{[2,}{ }^{3}$. Hence, there is an interest in better utilization of available power system capacities by installing new devices such as Flexible AC Transmission Systems (FACTS).

FACTS devices by controlling the power flows in the network without generation rescheduling or topological changes can improve the performance considerably $^{[4-6]}$. The insertion of such devices in electrical systems seems to be a promising strategy to decrease the transmission congestion and to increase available transfer capability. Using controllable components such as controllable series capacitors line flows can be changed in such a way that thermal limits are not violated, losses minimized, stability margins increased, contractual requirement fulfilled etc, without violating specific power dispatch. The increased interest in these devices is essentially due to two reasons. Firstly, the recent development in high power electronics has made these devices cost effective ${ }^{7]}$ and secondly, increased loading of power systems, combined with deregulation of power industry, motivates the use of power flow control as a very costeffective means of dispatching specified power transactions. It is important to ascertain the location for placement of these devices because of their considerable costs.

There are several methods for finding optimal locations of FACTS devices in both vertically integrated and unbundled power systems ${ }^{[8-12]}$. $\operatorname{In}^{[8]}$, a sensitivity approach based on line loss has been proposed for placement of series capacitors, phase shifters and static VAR (Volt Ampere Reactive) compensators. Other works in optimal power flow with FACTS devices ${ }^{[9,10]}$ have used optimization with different objective functions. In ${ }^{[13,14]}$, the optimal locations of FACTS devices are obtained by solving the economic dispatch problem plus the cost of these devices making the assumption that all lines, initially, have these devices. In the presence of bilateral and

Corresponding Author: Seyed Abbas Taher, Department of Electrical Engineering, University of Kashan, Kashan, Iran, Tel: +98-9131614352 
multilateral contracts it would be difficult to use this objective.

Congestion in a transmission system, whether vertically organized or unbundled, cannot be permitted except for very short duration, for fear of cascade outages with uncontrolled loss of load. Some corrective measures such as outage of congested branch, using FACTS devices, operation of transformer taps, redispatch of generation and curtailment of pool loads and/or bilateral contracts can relieve congestion.

A method to determine the optimal location of TCSC has been suggested in this paper. The approach is based on the sensitivity of the reduction of total system reactive power loss and real power performance index. In section 2 static modeling of TCSC is obtained. In section 3 the objective function for using in OPF (Optimal Power Flow) is presented. The optimal location is based on the minimizing the production and device cost. The proposed method has been demonstrated on two 5-bus power systems. The results show that above algorithm is suitable for relieving congestion and getting economical results.

\section{MATERIALS AND METHODS}

The Figure1.a shows a simple transmission line represented by its lumped $\pi$ equivalent parameters connected between bus-i and bus-j. Let complex voltage at bus-i and bus-j are $V_{i} \angle \delta_{i}$ and $V_{j} \angle \delta_{j}$ respectively. The real and reactive power flow from bus-i to bus-j can be written as

$$
\begin{aligned}
& P_{i j}=V_{i}^{2} G_{i j}-V_{i} V_{j}\left[G_{i j} \cos \left(\delta_{i j}\right)+B_{i j} \sin \left(\delta_{i j}\right)\right] \\
& Q_{i j}=-V_{i}^{2}\left(B_{i j}+B_{s h}\right)-V_{i} V_{j}\left[G_{i j} \sin \left(\delta_{i j}\right)-B_{i j} \cos \left(\delta_{i j}\right)\right]
\end{aligned}
$$

where $\delta_{i j}=\delta_{i}-\delta_{j}$. Similarly, the real and reactive power flow from bus-j to bus-i is

$$
\begin{aligned}
& P_{j i}=V_{j}^{2} G_{i j}-V_{i} V_{j}\left[G_{i j} \cos \left(\delta_{i j}\right)-B_{i j} \sin \left(\delta_{i j}\right)\right] \\
& Q_{j i}=-V_{j}^{2}\left(B_{i j}+B_{s h}\right)+V_{i} V_{j}\left[G_{i j} \sin \left(\delta_{i j}\right)+B_{i j} \cos \left(\delta_{i j}\right)\right]
\end{aligned}
$$

The model of transmission line with a TCSC connected between bus-i and bus-j is shown in Fig.1.b. During the steady state the TCSC can be considered as a static reactance $-j x_{c}$. The real and reactive power

flow from bus-i to bus-j, and from bus- $j$ to bus-i of a line having series impedance and a series reactance $\operatorname{are}^{[15]}$

$$
\begin{aligned}
& P_{i j}^{c}=V_{i}^{2} G_{i j}^{\prime}-V_{i} V_{j}\left(G_{i j}^{\prime} \cos \delta_{i j}+B_{i j}^{\prime} \sin \delta_{i j}\right) \\
& Q_{i j}^{c}=-V_{i}^{2}\left(B_{i j}^{\prime}+B_{s h}\right)-V_{i} V_{j}\left(G_{i j}^{\prime} \sin \delta_{i j}-B_{i j}^{\prime} \cos \delta_{i j}\right) \\
& P_{j i}^{c}=V_{j}^{2} G_{i j}^{\prime}-V_{i} V_{j}\left(G_{i j}^{\prime} \cos \delta_{i j}-B_{i j}^{\prime} \sin \delta_{i j}\right)
\end{aligned}
$$

$$
Q_{j i}^{c}=-V_{j}^{2}\left(B_{i j}^{\prime}+B_{s h}\right)+V_{i} V_{j}\left(G_{i j}^{\prime} \sin \delta_{i j}+B_{i j}^{\prime} \cos \delta_{i j}\right)
$$

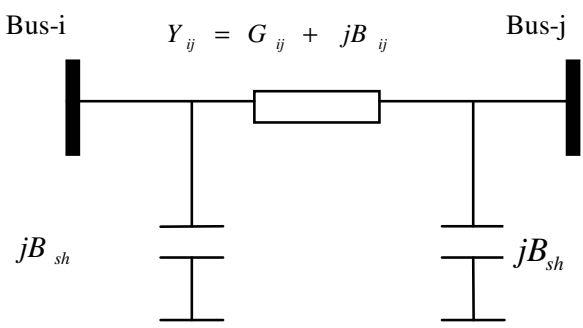

(a)

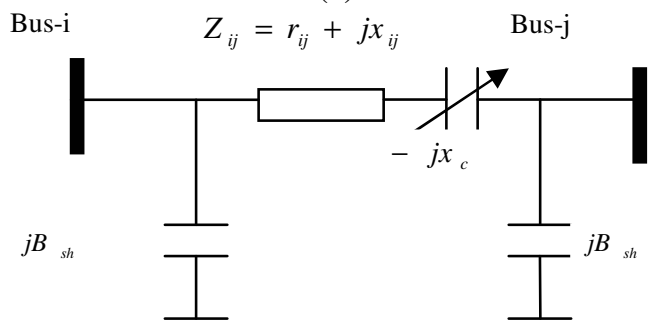

(b)

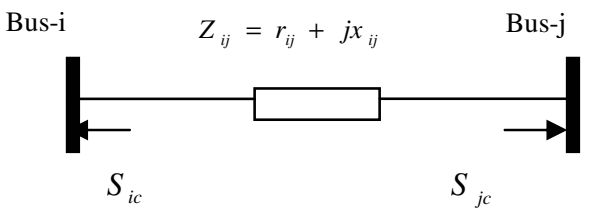

(c)

Fig.1: (a) Model of Transmission line (b) Model of TCSC (c) Injection Model of TCSC

The active and reactive power loss in the line having TCSC can be written as

$$
\begin{aligned}
& P_{L}=P_{i j}+P_{j i}=G_{i j}^{\prime}\left(V_{i}^{2}+V_{j}^{2}\right)-2 V_{i} V_{j} G_{i j}^{\prime} \cos \delta_{i j} \\
& Q_{L}=Q_{i j}+Q_{j i}=-\left(V_{i}^{2}+V_{j}^{2}\right)\left(B_{i j}^{\prime}+B_{s h}\right)+2 V_{i} V_{j} B_{i j}^{\prime} \cos \delta_{i j}
\end{aligned}
$$

where $G_{i j}^{\prime}=\frac{r_{i j}}{r_{i j}^{2}+\left(x_{i j}-x_{c}\right)^{2}}$ and $B_{i j}^{\prime}=\frac{-\left(x_{i j}-x_{c}\right)}{r_{i j}^{2}+\left(x_{i j}-x_{c}\right)^{2}}$.

The change in the line flow due to series capacitance can be represented as a line without series capacitance with power injected at the receiving and sending ends of the line as shown in Fig.1.c. The real and reactive power injections at bus-i and bus-j can be expressed as

$$
P_{i c}=V_{i}^{2} \Delta G_{i j}-V_{i} V_{j}\left[\Delta G_{i j} \cos \delta_{i j}+\Delta B_{i j} \sin \delta_{i j}\right]
$$




$$
\begin{aligned}
& P_{j c}=V_{j}^{2} \Delta G_{i j}-V_{i} V_{j}\left[\Delta G_{i j} \cos \delta_{i j}-\Delta B_{i j} \sin \delta_{i j}\right] \\
& Q_{i c}=-V_{i}^{2} \Delta B_{i j}-V_{i} V_{j}\left[\Delta G_{i j} \sin \delta_{i j}-\Delta B_{i j} \cos \delta_{i j}\right] \\
& Q_{j c}=-V_{j}^{2} \Delta B_{i j}+V_{i} V_{j}\left[\Delta G_{i j} \sin \delta_{i j}+\Delta B_{i j} \cos \delta_{i j}\right]
\end{aligned}
$$

where $\quad \Delta G_{i j}=\frac{x_{c} r_{i j}\left(x_{c}-2 x_{i j}\right)}{\left(r_{i j}^{2}+x_{i j}^{2}\right)\left(r_{i j}^{2}+\left(x_{i j}-x_{c}\right)^{2}\right)}$ and

$$
\Delta B_{i j}=\frac{-x_{c}\left(r_{i j}^{2}-x_{i j}^{2}+x_{c} x_{i j}\right)}{\left(r_{i j}^{2}+x_{i j}^{2}\right)\left(r_{i j}^{2}+\left(x_{i j}-x_{c}\right)^{2}\right)} \text {. }
$$

Due to high cost of FACTS devices, it is necessary to use cost-benefit analysis to analyze whether new FACTS device is cost effective among several candidate locations where they actually installed. The TCSC cost in line-k is given by ${ }^{[16]}$,

$$
C_{T C S C}(k)=c . x_{c}(k) \cdot P_{L}^{2} \cdot \text { Base }
$$

where $\mathrm{c}$ is the unit investment cost of FACTS, $x_{c}(k)$ is the series capacitive reactance and $P_{L}$ is the power flow in line-k. be

The objective function for placement of TCSC will

$$
\min _{P_{i}} \sum_{i} C_{i}\left(P_{i}\right)+C_{T C S C}
$$

\section{OPTIMAL LOCATION OF TCSC}

Reduction of total system reactive power loss: Here we look at a method based on the sensitivity of the total system reactive power loss with respect to the control variable of the TCSC. For TCSC placed between buses $\mathrm{i}$ and $\mathrm{j}$ we consider net line series reactance as a control parameter. Loss sensitivity with respect to control parameter of TCSC placed between buses $\mathrm{i}$ and $\mathrm{j}$ can be written as

$$
a_{i j}=\frac{\partial Q_{L}}{\partial x_{i j}}=\left[V_{i}^{2}+V_{j}^{2}-2 V_{i} V_{j} \cos \delta_{i j}\right] \cdot \frac{r_{i j}^{2}-x_{i j}^{2}}{\left(r_{i j}^{2}+x_{i j}^{2}\right)^{2}}
$$

Real power flow performance index sensitivity indices: The severity of the system loading under normal and contingency cases can be described by a real power line flow performance index ${ }^{[17]}$, as given below.

$$
P I=\sum_{m=1}^{N_{L}} \frac{w_{m}}{2 n}\left(\frac{P_{L m}}{P_{L m}^{\max }}\right)^{2 n}
$$

where $P_{L m}$ is the real power flow and $P_{L m}^{\max }$ is the rated capacity of line- $\mathrm{m}, \mathrm{n}$ is the exponent and $w_{m}$ a real nonnegative weighting coefficient which may be used to reflect the importance of lines.
PI will be small when all the lines are within their limits and reach a high value when there are overloads. Thus, it provides a good measure of severity of the line overloads for given state of the power system. Most of the works on contingency selection algorithms utilize the second order performance indices which, in general, suffer from masking effects. The lack of discrimination, in which the performance index for a case with many small violations may be comparable in value to the index for a case with one huge violation, is known as masking effect. By most of the operational standards, the system with one huge violation is much more severe than that with many small violations. Masking effect to some extent can be avoided using higher order performance indices, that is $\mathrm{n}>1$. However, in this study, the value of exponent has been taken as 2 and $w_{i}=1$.

The real power flow PI sensitivity factors with respect to the parameters of TCSC can be defined as

$b_{k}=\left.\frac{\partial P I}{\partial x_{c k}}\right|_{x_{c k}=0}$

The sensitivity of PI with respect to TCSC parameter connected between bus-i and bus- $j$ can be written as

$\frac{\partial P I}{\partial x_{c k}}=\sum_{m=1}^{N_{L}} w_{m} P_{L m}^{3}\left(\frac{1}{P_{L m}^{\max }}\right)^{4} \frac{\partial P_{L m}}{\partial x_{c k}}$

The real power flow in a line-m can be represented in terms of real power injections using DC power flow equations ${ }^{[17]}$ where $s$ is slack bus, as

$P_{L m}= \begin{cases}\sum_{\substack{n=1 \\ n \neq s}}^{N} S_{m n} P_{n} & \text { for } m \neq k \\ \sum_{\substack{n=1 \\ n \neq s}}^{N} S_{m n} P_{n}+P_{j} & \text { for } m=k\end{cases}$

Using equation (21), the following relationship can be derived,

$$
\frac{\partial P_{L m}}{\partial x_{c k}}= \begin{cases}\left(S_{m i} \frac{\partial P_{i}}{\partial x_{c k}}+S_{m j} \frac{\partial P_{j}}{\partial x_{c k}}\right) & \text { for } m \neq k \\ \left(S_{m i} \frac{\partial P_{i}}{\partial x_{c k}}+S_{m j} \frac{\partial P_{j}}{\partial x_{c k}}\right)+\frac{\partial P_{j}}{\partial x_{c k}} & \text { for } m=k\end{cases}
$$

The terms $\left.\frac{\partial P_{i}}{\partial x_{c k}}\right|_{x_{c k}=0},\left.\frac{\partial P_{j}}{\partial x_{c k}}\right|_{x_{c k}=0}$ can be derived as below

$$
\begin{aligned}
& \left.\frac{\partial P_{i}}{\partial x_{c k}}\right|_{x_{c k}=0}=\left.\frac{\partial P_{i c}}{\partial x_{c k}}\right|_{x_{c k}=0} \\
& =-2\left(V_{i}^{2}-V_{i} V_{j} \cos \delta_{i j}\right) \frac{r_{i j} x_{i j}}{\left(r_{i j}^{2}+x_{i j}^{2}\right)^{2}}-V_{i} V_{j} \sin \delta_{i j} \frac{\left(x_{i j}^{2}-r_{i j}^{2}\right)}{\left(r_{i j}^{2}+x_{i j}^{2}\right)^{2}}
\end{aligned}
$$




$$
\begin{aligned}
& \left.\frac{\partial P_{j}}{\partial x_{c k}}\right|_{x_{c k}=0}=\left.\frac{\partial P_{j c}}{\partial x_{c k}}\right|_{x_{c k}=0} \\
& =-2\left(V_{j}^{2}-V_{i} V_{j} \cos \delta_{i j}\right) \frac{r_{i j} x_{i j}}{\left(r_{i j}^{2}+x_{i j}^{2}\right)^{2}}+V_{i} V_{j} \sin \delta_{i j} \frac{\left(x_{i j}^{2}-r_{i j}^{2}\right)}{\left(r_{i j}^{2}+x_{i j}^{2}\right)^{2}}
\end{aligned}
$$

Criteria for optimal location: The FACTS device should be placed on the most sensitive line. With the sensitivity indices computed for TCSC, following criteria can be used for its optimal placement.

a) In reactive power loss reduction method TCSC should be placed in a line having the most positive loss sensitivity index.

b) In PI method TCSC should be placed in a line having most negative sensitivity index.

\section{RESULTS AND DISCUSSION}

The approach has been examined on two 5-bus power systems. MATPOWER, a toolbox of MATLAB, has been used for simulations ${ }^{[18]}$. The prices bid by generators for each 5-bus system are given in Table 1 where $\mathrm{P}$ is in $\mathrm{MW}$ and $\$$ is a momentary unit which may be scaled by any arbitrary constant without affecting the results and $P_{i \min }, P_{i \max }$ are generation power limits of each generator.

Table 1: Bid prices of generators

\begin{tabular}{cccc}
\hline Generator & Bid Prices $(\$ / \mathrm{h})$ & $P_{i \min }$ & $P_{i \max }$ \\
\hline 1 & $0.11 P_{1}^{2}+5 P_{1}+150$ & 10 & 250 \\
2 & $0.085 P_{2}^{2}+1.2 P_{2}+60$ & 10 & 200 \\
3 & $0.1225 P_{3}^{2}+P_{3}+335$ & 10 & 200 \\
\hline
\end{tabular}

The first 5-bus system is shown in Fig.2.a. Bus-1 has been taken as a reference bus.

From the load flow, it was found that real power flow in line 2-5 was 1.034 pu which is more than its line loading limit.

The sensitivities of reactive power loss reduction and real power flow performance index with respect to TCSC control parameter has been computed and are shown in Table 2. The sensitive line in each case is presented in bold type. It can be observed from Table 2 (column 3) that placement of TCSC in line-3 is suitable for reducing the total reactive power loss. System power flow result after placing TCSC in line-3 is shown in Table 3 (column 4). The value of control parameter of TCSC for computing power flow is taken as 0.2885 pu. It can be observed from Table 3 (column 4) that congestion has been relieved. Placement of TCSC in line-1 also will reduce the total system reactive power loss but it will be less effective than placing a TCSC in line- 3 as can be seen from its sensitivity factors.

It can be observed from Table 2 (column 4) that placing a TCSC in line-5 is optimal for reducing the PI and congestion relief. System power flow result after placing TCSC in line-5 is shown in Table 3 (column 5). The value of control parameter of TCSC for computing power flow is taken as $0.0423 \mathrm{pu}$. It can be observed from Table 3 (column 5) that congestion has been relieved.

Placement of TCSC in line-3 will reduce the PI value but it will be less effective than placing a TCSC in line-5 as can be seen from its sensitivity factors. Total costs of two methods are shown in Table 6. It can be observed from Table 6 that reduction of total system reactive power loss method is more economical than PI method for placing the TCSC and congestion management.

Table 2: Calculated sensitivity indices of first 5-bus system

\begin{tabular}{cccc}
\hline Line & $\mathrm{i}-\mathrm{j}$ & $a_{i j}$ & $b_{i j}$ \\
\hline 1 & $2-1$ & -0.008057 & -0.0789 \\
2 & $2-5$ & -0.970852 & 1.95327 \\
3 & $3-5$ & -0.00784 & -0.10536 \\
4 & $5-4$ & -0.261704 & 0.34953 \\
5 & $1-4$ & -0.967394 & -0.41433 \\
6 & $3-2$ & -0.240349 & 0.45582 \\
\hline
\end{tabular}

Table 3: Power flow result of first 5-bus system

\begin{tabular}{ccccc}
\hline Line & $\mathrm{i}-\mathrm{j}$ & $\begin{array}{c}\text { Power flow } \\
\text { without } \\
\text { TCSC } \\
(\mathrm{pu})\end{array}$ & $\begin{array}{c}\text { Power flow } \\
\text { with TCSC } \\
\text { in Line-3 } \\
(\mathrm{pu})\end{array}$ & $\begin{array}{c}\text { Power flow } \\
\text { with TCSC } \\
\text { in Line-5 } \\
(\mathrm{pu})\end{array}$ \\
1 & $2-1$ & 0.07798 & 0.07614 & 0.10893 \\
2 & $2-5$ & 1.034 & 0.99956 & 0.99956 \\
3 & $3-5$ & 0.08441 & 0.08441 & 0.08798 \\
4 & $5-4$ & 0.40379 & 0.40379 & 0.37453 \\
5 & $1-4$ & 0.4145 & 0.41123 & 0.46051 \\
6 & $3-2$ & 0.51559 & 0.47879 & 0.51202 \\
\hline
\end{tabular}

The second 5-bus system is shown in Fig.2.b. Bus1 has been taken as a reference bus.

From the load flow, it was found that real power flow in line 1-2 was $1.0181 \mathrm{pu}$ which is more than its line loading limit. 


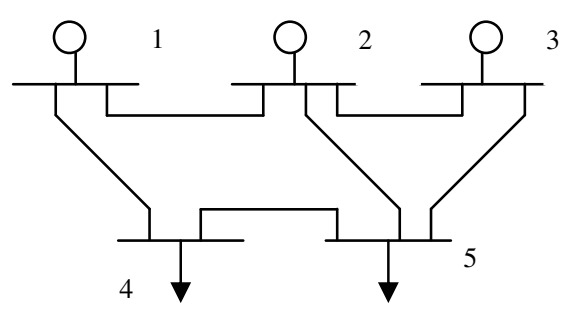

(a)

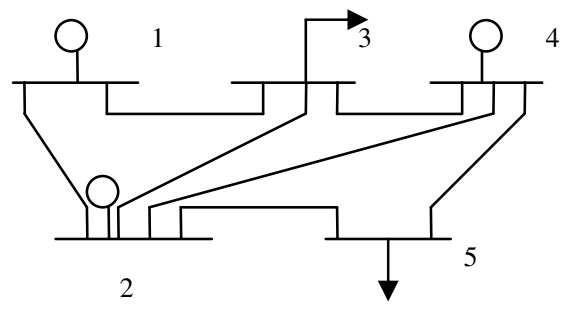

(b)

Fig.2 (a): First 5-bus system (b) Second 5-bus system

The sensitivities of reactive power loss reduction and real power flow performance index with respect to TCSC control parameter has been computed and are shown in Table 4. The sensitive line in each case is presented in bold type. It can be observed from Table 4 (column 3) that placement of TCSC in line-6 will reduce the total system reactive power loss but it will be less effective than placing a TCSC in line-7 as can be seen from its sensitivity factors. System power flow result after placing TCSC in line-7 is shown in Table 5 (column 4). The value of control parameter of TCSC for computing power flow is taken as 0.17815 pu. It can be observed from Table 5 (column 4) that congestion has been relieved. From the calculated sensitivity factors $b_{i j}$ of Table 4 (column 4) it can be observed that placement of TCSC in line-7 will reduce the PI but it will be less effective than placing a TCSC in line-2. System power flow result after placing TCSC in line-2 is shown in Table 5 (column 5). The value of control parameter of TCSC for computing power flow is taken as $0.014315 \mathrm{pu}$. It can be observed from Table 5 (column 5) that congestion has been relieved. Total costs of two methods are shown in Table 6. It can be observed from Table 6 that PI method in this case is more economical than reduction of total system reactive power loss method for installing the TCSC and congestion relief.
Table 4: Calculated sensitivity indices of second 5-bus

\begin{tabular}{cccc} 
system & & & \\
\hline Line & $\mathrm{i}-\mathrm{j}$ & $a_{i j}$ & $b_{i j}$ \\
\hline 1 & $1-2$ & -1.20822 & 3.45 \\
2 & $1-3$ & -0.19303 & $\mathbf{- 1 . 1 1}$ \\
3 & $2-3$ & -0.18757 & 0.609 \\
4 & $2-4$ & -0.10456 & 0.124 \\
5 & $2-5$ & -0.60931 & 1.39 \\
6 & $3-4$ & -0.05629 & 0.15 \\
7 & $4-5$ & -0.0368 & -0.18 \\
\hline
\end{tabular}

Table 5: Power flow result of second 5-bus system

\begin{tabular}{ccccc}
\hline Line & $\mathrm{i}-\mathrm{j}$ & $\begin{array}{c}\text { Power flow } \\
\text { without } \\
\text { TCSC } \\
(\mathrm{pu})\end{array}$ & $\begin{array}{c}\text { Power flow } \\
\text { with TCSC in } \\
\text { line-7 } \\
(\mathrm{pu})\end{array}$ & $\begin{array}{c}\text { Power flow } \\
\text { with TCSC } \\
\text { in line-2 } \\
(\mathrm{pu})\end{array}$ \\
\hline 1 & $1-2$ & 1.0181 & 0.99956 & 0.99956 \\
2 & $1-3$ & 0.48796 & 0.50718 & 0.50751 \\
3 & $2-3$ & 0.43934 & 0.48785 & 0.42892 \\
4 & $2-4$ & 0.33076 & 0.37522 & 0.32527 \\
5 & $2-5$ & 0.76539 & 0.65385 & 0.76276 \\
6 & $3-4$ & 0.1133 & 0.17992 & 0.12135 \\
7 & $4-5$ & 0.14286 & 0.25336 & 0.14546 \\
\hline
\end{tabular}

Table 6: Total cost

\begin{tabular}{|c|c|c|}
\hline Power system & Method & $\begin{array}{l}\text { Total } \\
\text { Cost }\end{array}$ \\
\hline \multirow{2}{*}{$\begin{array}{l}\text { First 5-bus } \\
\text { system }\end{array}$} & $\begin{array}{l}\text { Reactive loss } \\
\text { reduction }\end{array}$ & 2250.11 \\
\hline & PI & 2276.78 \\
\hline \multirow{2}{*}{$\begin{array}{l}\text { Second 5-bus } \\
\text { system }\end{array}$} & $\begin{array}{l}\text { Reactive loss } \\
\text { reduction }\end{array}$ & 5040.51 \\
\hline & PI & 4929.44 \\
\hline
\end{tabular}

\section{CONCLUSION}

Congestion management is an important issue in deregulated power systems. FACTS devices such as TCSC by controlling the power flows in the network can help to reduce the flows in heavily loaded lines. Because of the considerable costs of FACTS devices, it is important to obtain optimal location for placement of these devices.

In this paper two sensitivity-based methods have been developed for determining the optimal location of TCSC in an electricity market. In a system, first two optimal locations of TCSC can be achieved based on the sensitivity factors $a_{i j}$ and $b_{i j}$ and then optimal location is selected based on minimizing production cost plus device cost. Test results obtained on two 5-bus power systems show that sensitivity factors along with 
TCSC cost could be effectively used for determining optimal location of TCSC.

\section{REFERENCES}

1. Kumar A., Srivastava S.C., Singh S.N., 2004. A Zonal Congestion Management Approach Using Real and Reactive Power Rescheduling, IEEE Transactions on Power Systems, Vol. 19, No. 1.

2. Vries L.J., 2001. Capacity allocation in a restructured electricity market: technical and economic evaluation of congestion management methods on interconnectors, Proc. IEEE Porto Power Tech Conf.

3. Lommerdal M., Soder L., 2003. Simulation of Congestion Management Methods, Proc. Bologna Power Tech.

4. Baldick R., Kahn E., 1997. Contract paths, phase shifters and efficient electricity trade, IEEE Transactions on Power Systems, Vol. 12, No. 2: 749-755.

5. Bladow J., Montoya A., 1991. Experiences with parallel EHV phase shifting transformers, IEEE Transactions on Power Delivery, 1096-1100.

6. Galiana G.D., 1996. Assesment and control of the impact of FACTS devices on power system performance, IEEE Transactions on Power System, Vol. 11, No. 4: 1931-1936.

7. Larsen E., Millers N., Nilsson S., Lindgren S., 1992. Benefits of GTO-Based compensation systems for electric utility applications, IEEE Transactions on Power Delivery, Vol. 7, No. 4: 2056-2064.

8. Preedavinchit P., Srivastava S.C., 1998. Optimal reactive power dispatch considering FACTS devices, Electric Power Systems Research, Vol. 46, No. 3: 251-257.
9. Huang G., Hsieh S.C., 1998. Fast textured algorithms for optimal delivery problems in deregulated environments, IEEE Trans. on Power Systems, Vol. 13, No. 2: 493-500.

10. Momoh J.A., Zhu J.Z., 1998. A new approach to optimal power flow with phase shifter, IEEE International Conference on Systems, Vol. 5: 47944799.

11. Wu G., Yokoyama A., He J., Yu Y., 1998. Allocation and control of FACTS devices for steady state stability enhancement of large scale power system, IEEE International Conference on Power System Technology, Vol. 1: 357-361.

12. Liu J.Y., Song Y.H., 1999. Comparison studies of unified power flow controller with static var compensators and phase shifters, Electric Machines and Power Systems, Vol. 27: 237-251.

13. Lie T.T., Deng W., 1999. Optimal flexible AC transmission systems (FACTS) devices allocation, International Journal of Electrical Power and Energy Systems, Vol. 19, No. 2 : 125-134.

14. De Oliveira E.J., Lima W.M., 1999 Allocation of FACTS devices in a competitive environment, 13th PSCC, 1184-1190.

15. Verma K.S., Singh S.N., Gupta H.O., 2001. FACTS devices location for enhancement of total transfer capability, Power Engineering Society Winter Meeting, IEEE, Vol. $2: 522-527$.

16. Singh S.N., David A.K., 2000. Placement of FACTS devices in open power market, Advances in Power System Control, Operation and Management, Vol. 1 : 173-177.

17. Wood A.J., Wollenberg B.F., 1996. Power Generation, Operation and Control, John Wiley, New York.

18. MATPOWER, a MATLAB Power System Simulation Package, Version 3.0.0, http://www.pserc.cornell.edu/matpower. 